\title{
THE LAST LARVA AND POST-LARVA OF TYPTON SPONGICOLA FROM PLYMOUTH (CRUSTACEA DECAPODA)
}

\author{
By Marie V. Lebour, D.Sc. \\ From the Plymouth Laboratory
}

(Text-figs. I-4)

The first larva of Typton spongicola was described in 1925 from the eggs carried by the parent (Lebour, 1925). No later stages are known; therefore it was interesting to find a last larva in the plankton from 2 miles north-east of the Eddystone (2I August I946), which changed to the post-larva in the laboratory. There seems to be no doubt that the identification is correct although, surprisingly, the antennal scale, rudimentary in the adult, is still large. The agreement in colour of the last larva and post-larva with the newly hatched first larva, and the great similarity in the structure, in most ways, of post-larva and adult, makes it practically certain that we are dealing with T. spongicola.

A specimen of a post-larval Typton, almost certainly $T$. tortugae, was found in one of Dr Hilary Moore's hauls from Bermuda in I940. This is much smaller than the Plymouth post-larva, but a good deal further advanced, having no antennal scale, and is interesting for comparison with $T$. spongicola.

\section{Typton spongicola Costa (Figs I-3)}

\section{The Last Larva}

The last larva measured c. $4.8 \mathrm{~mm}$. in length, but it is difficult to be exact because of the internally bent body, the abdominal hump coming up close to the head and the legs bent up parallel to the body, the antennules and antennae held straight out. This is distinctly of the Mesocaris type (see Gurney, I938; Gurney \& Lebour, I94I), with the body doubly flexed and legs 3-5 equal or sub-equal and not elongated. The colour is deep orange with red spots, most of the sixth abdominal somite, telson and uropods colourless, agreeing with the colour of the first larva. The animal makes sideway leaps in much the same way as do so many of the hump-backed larvae of similar form, so numerous in the Bermuda plankton. There are setose exopods on legs $\mathrm{I}-4$, but not on 5 , leg 5 being very slightly longer than legs 2 and 3 . This larva changed to the post-larva in the laboratory (26 August 1946), and the following description is taken from the cast skin. The rostrum is short and pointed with one spine 
dorsally. The carapace has a small supra-orbital spine and a short spine probably to be regarded as antennal, and there is a point at the outer anterior angle. The abdominal somites are rounded, the sixth being very long, longer than $2-5$ combined, the uropods slightly pointed, the telson long with one
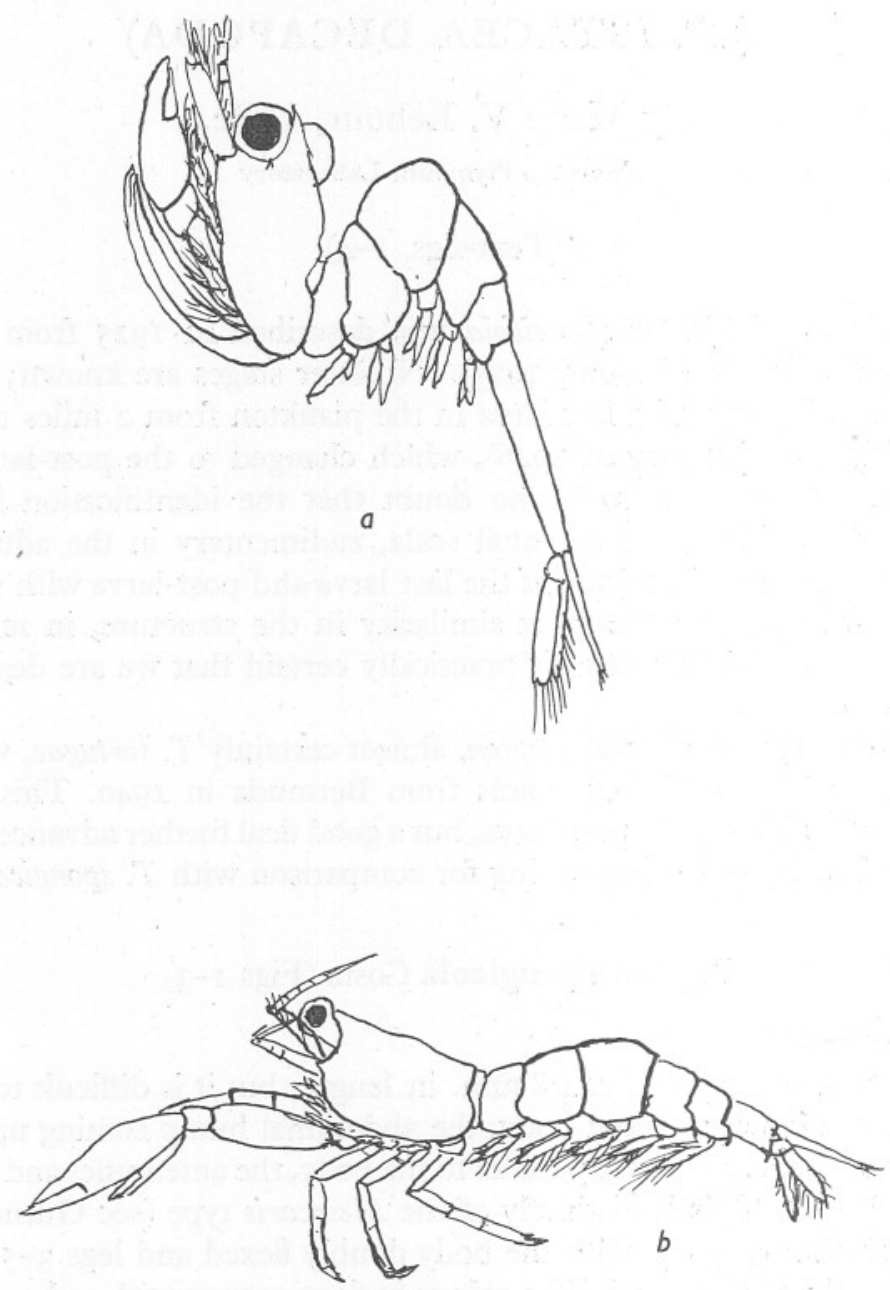

Fig. I. Typton spongicola. Sketch from life of $(a)$ the last larva, $(b)$ the post-larva from last larva.

pair of lateral spines and 8 terminal setae, the outermost the longest, the third from the outside next in length, the inner setae very short. The antennule has two short branches, a tooth on the outer margin of the base and a small tooth near the centre of the basal segment. The antenna has a short segmented flagellum and a well-developed scale. The mandible has a grinding and 


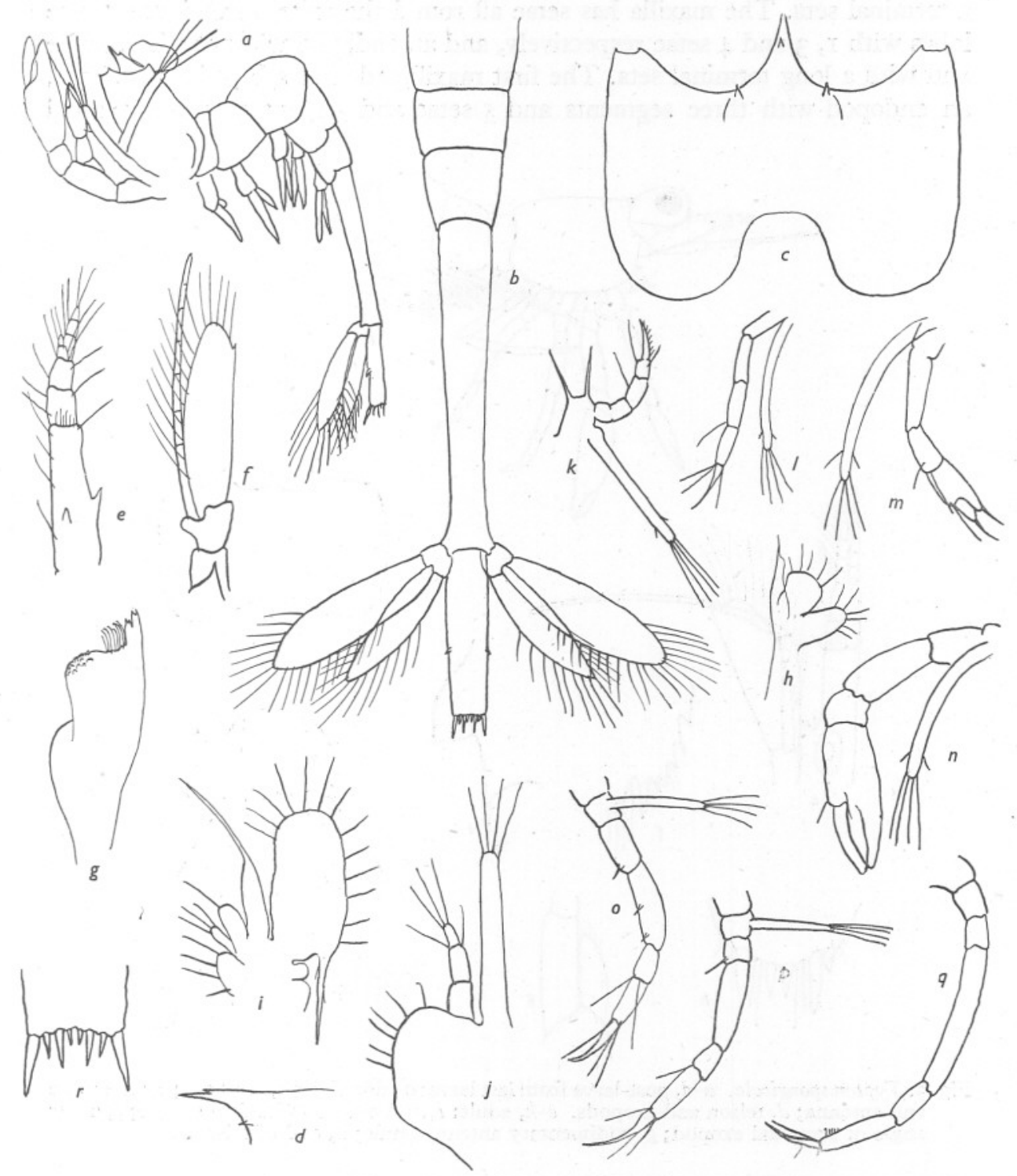

Fig. 2. Last larva of Typton spongicola: $a$, cast skin of body; $b$, abdomen and tail fan; $c$, carapace; $d$, rostrum; $e$, antennule; $f$, antenna; $g$, mandible; $h$, maxillule; $i$, maxilla; $j$, first maxillipede; $k$, second maxillipede; $l$, third maxillipede; $m$, first leg; $n$, second leg; $o$, third leg; $p$, fourth leg; $q$, fifth leg; $r$, end of telson. 
cutting edge, the maxillule with two inner setose lobes and an endopod with a terminal seta. The maxilla has setae all round the exite, three inner setose lobes with I, 3 and 4 setae respectively, and an endopod without a basal lobe and with a long terminal seta. The first maxillipede has a broad setose base, an endopod with three segments and 5 setae and an unsegmented exopod

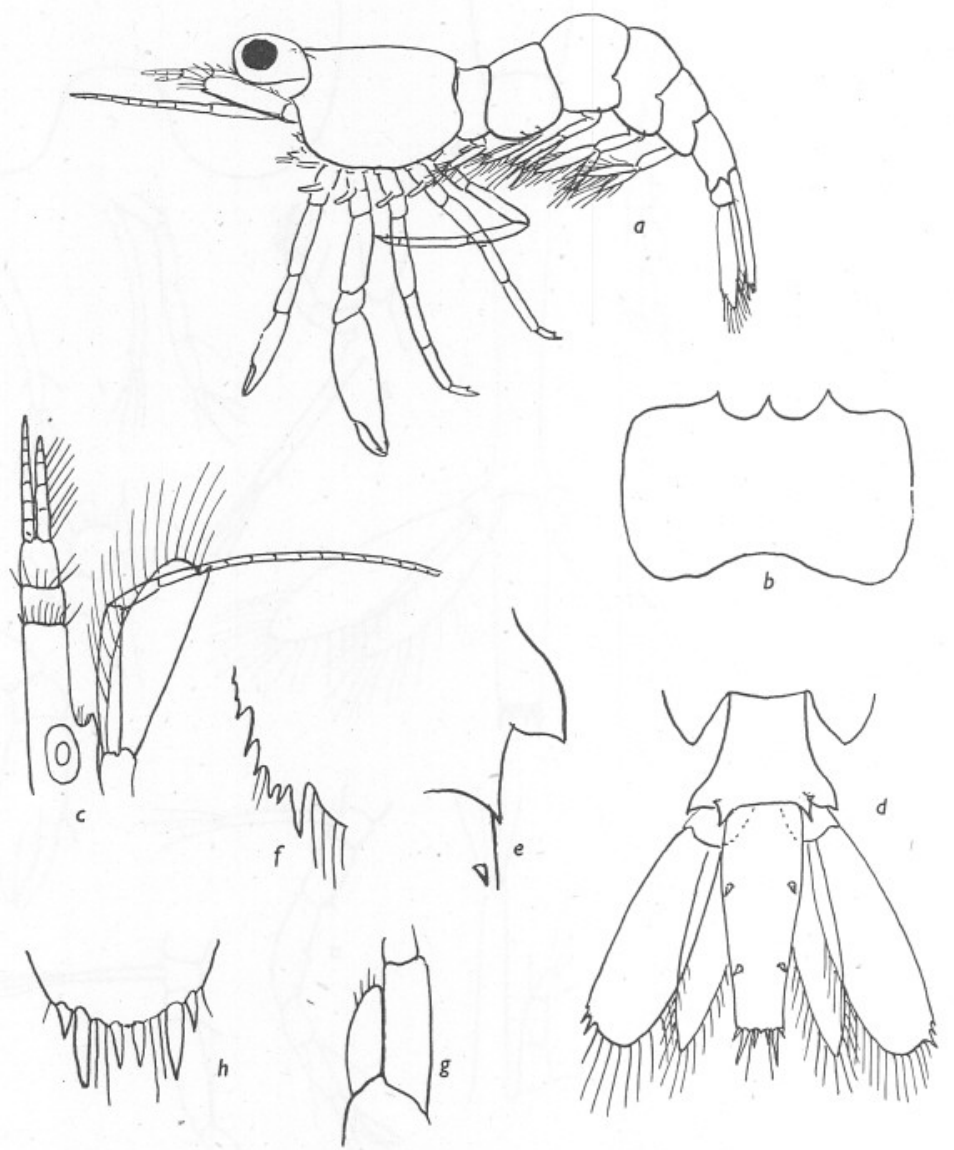

Fig. 3. Typton spongicola. $a-d$, post-larva from last larva: $a$, side view; $b$, carapace; $c$, antennule and antenna; $d$, telson and uropods. $e-h$, adult: $e$, end of last abdominal somite; $f$, outer angle of uropodal exopod; $g$, rudimentary antennal scale; $h$, end of telson.

with 4 setae. The second maxillipede has a broad base with 2 strong setae, a 4-segmented endopod ending in a strong hook and an unsegmented exopod with 6 setae. This strongly resembles the second maxillipede in the first stage, as does also the third maxillipede, the endopod of which ends in a strong claw with stout setae at the base. The first leg has an exopod with 6 setae and a chelate endopod; the second leg is similar but longer with a larger chela; 
the third and fourth legs are sub-equal with 4 setae on the exopod, the endopod ending in a long pointed dactyl; the fifth leg is slightly longer and without an exopod. There are no setae on the pleopods.

\section{The Post-Larva}

The Post-larva from the last larva measures $3.8 \mathrm{~mm}$. long and is no longer doubly flexed, but the abdomen is held out nearly straight with a slight dorsal hump (Fig. I $b$ ). The colouring is much the same as in the last larva, but the orange extends on to most of the abdominal somites, the telson and uropods still being colourless. There is a short unarmed rostrum and an antennal spine, the other spines having disappeared. The antennule does not differ much from the last larva and there is still an antennal scale, although it is somewhat shorter, the breadth being greater compared with the length. The flagellum is about twice as long as the scale. The abdomen is similar in shape to that of the adult, the ends of somites 4 and 5 ending in rounded points. The sixth somite is very much shorter than in the last larva and bears two broad spines, each side posteriorly very much as in the adult. The telson is straighter and narrower than in the adult, but is similarly armed with two pairs of lateral spines and three pairs of stout spines at the end with a minute central tooth. There is also a pair of hairs in the post-larva and more in the adult between the spines. The outer angle of the uropodal exopod in the adult has a main spine and seven small spines outside it; these latter are represented in the post-larva by two spines outside the main one. Except for the continued presence of the antennal scale the post-larva agrees very well with the adult. The mouthparts were not examined. There are remains of exopods on legs I-4, and the first and second legs are much the same as in the last larva, the second legs being about equal and not as in the adult of unequal length. Legs $3-5$ end in short dactyls as in the adult. The second legs are held straight in front of the body in life and the antennules and antennae stick up in front with the flagella doubled back. It appears to be likely that the postlarva swims about before entering the sponge and perhaps undergoes several moults before entering a sedentary life. No young stages have so far been found in the sponge.

\section{Typton tortugae Smith (Fig. 4)}

The post-larva was found in one of Dr Moore's Bermuda hauls in I940. It is only $2.9 \mathrm{~mm}$. in length, and there is no antennal scale, thus differing conspicuously from $T$. spongicola. The legs agree very well with Schmitt's figure and there seems to be no doubt that it belongs to this species. There are remains of exopods on legs I and 2 only, and not on legs 3-5. Gurney and Lebour (I94I) have described a larva (Mesocaris A) from Bermuda which they suggest might belong to $T$. tortugae. This has exopods on legs $\mathrm{I}-4$, which seem to exclude it from this species whose larva is thus still to be found. 

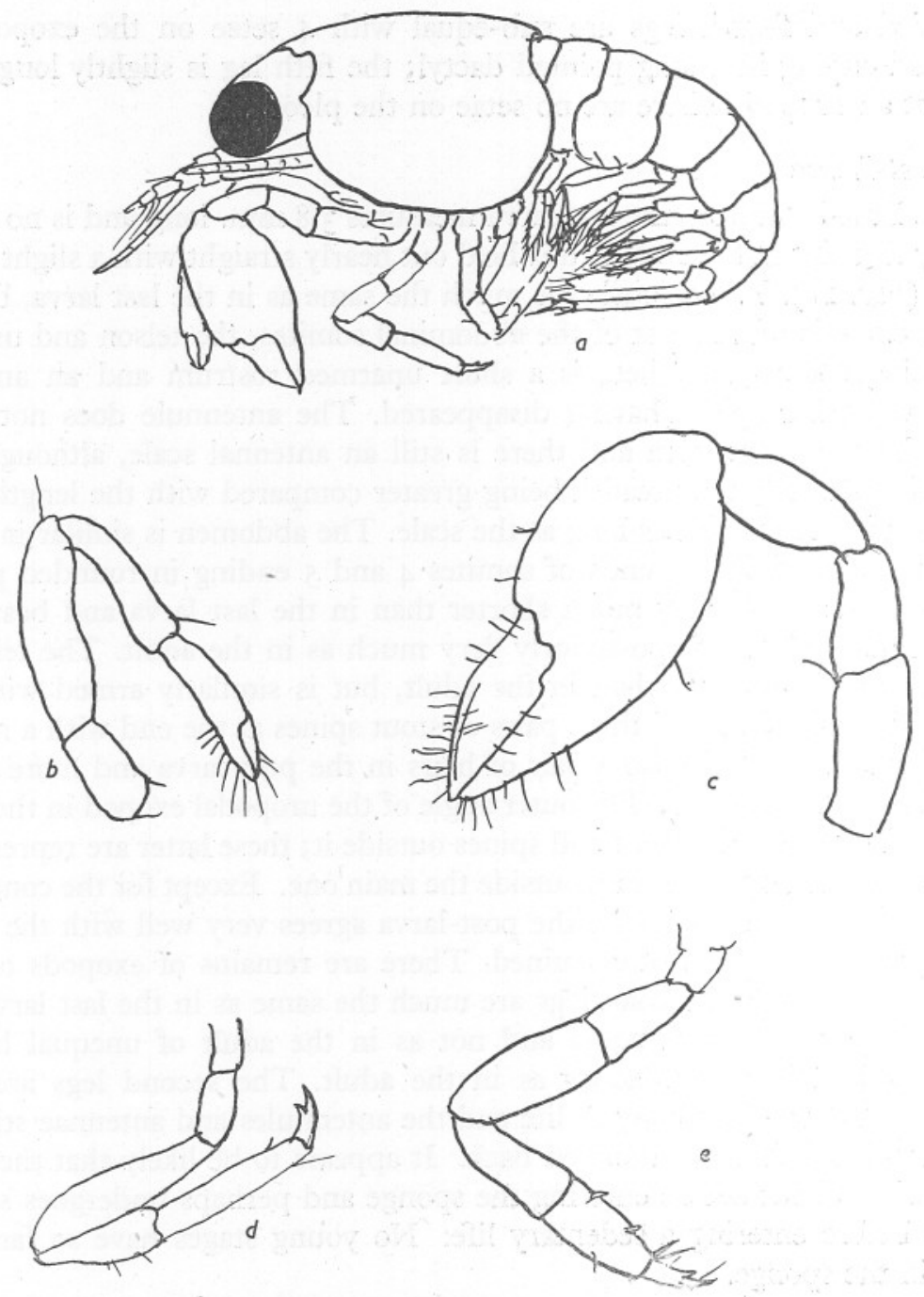

Fig. 4. Typton tortugae, post-larva: $a$, side view; $b-e$, legs $\mathrm{I}-4$.

\section{REFERENCES}

GuRney, R., I938. The larvae of the decapod crustacea Palaemonidae and Alpheidae. Sci. Rep. Gr. Barrier Reef Exped., Vol. vI, pp. I-6o.

GuRney, R. \& Lebour, M. V., I94I. On the larvae of certain crustacean Macrura, mainly from Bermuda. Fourn. Linn. Soc. (Zool.), Vol. XLI, pp. 9I-I8I.

Lebour, M. V., i925. The eggs and newly hatched larva of Typton spongicola O. G. Costa. Fourn. Mar. Biol. Assoc., Vol. xiII, pp. 848-53.

Schmit, W. L., 1930. Some observations on the Crustacea of Tortugas, Florida. Year Book Carneg. Instn 1929-30, No. 29, pp. 343-6. 